\title{
The role of individuals' risk representations in risk management - case-study on lahars in Arequipa (Peru)
}

\author{
Carine Heitz ${ }^{1 *}$ and Miriam Nagata Shimabuku²
}

\begin{abstract}
Background: In risk-prone areas, measuring risk representation can help implementing communication and disclosing information among the population, in order to increase individual initiatives to protect themselves and their properties or to provide a better knowledge of the appropriate measures to be adopted during or after a disaster. The perceived legitimacy of authorities disclosing information is a key issue in individuals' beliefs. Then, to compel the population to follow the authorities' recommendations and to adopt the suitable behaviour in case of a disaster, the information needs to be targeted, in order to take into account (a) the individuals' representation of the risk they incur and (b) the level of legitimacy received from the authorities in charge of risk management. Consequently, the question of the modalities to qualify the relations between information and representation and risk management arises?

Results: To solve this issue at the foot of El Misti Volcano (Arequipa, Peru), we conducted surveys in lahars (debris flows on and from volcanic slopes)-prone areas and unexposed ones. The methodology is based on selfadministrated questionnaires $(N=209)$. The results show that respondents endow legitimacy in risk reduction (more than 70\%) to a national authority (Defensa Civil) in charge of the management of risk in the city of Arequipa. More than $64 \%$ of the respondents consider that they are not sufficiently informed on the behaviours to adopt in case of a disaster. It leads to a weak implication of the respondents in the adoption of individual initiatives to protect themselves (23\%) and to important expectations towards authorities' actions in decreasing their vulnerability (50\%).

Conclusion: Such results are relevant to other context as mentioned in the literature: knowing the nature of the link between self-protection, prevention policies and national regulation is essential to decide the best way to manage risk.
\end{abstract}

Keywords: Risk representation, Information, Communication, Risk management, Surveys

\section{Background}

The literature abounds in studies questioning the representation of population exposed to natural hazard (Grothmann and Reusswig 2006; Joffe 2003; Paton et al., 2000; Perry and Lindell 2008; Renn 2004; Sjöberg 2000; Slovic et al. 2004; Slovic and Peters 2006; Wachinger et al. 2013; November and Leanza 2016). This literature also assumes that preventive information campaigns impacts on the individuals' behaviours exposed to hazards, whether they are natural or

\footnotetext{
* Correspondence: carine.heitz@irstea.fr

'Irstea, UMR GESTE, ENGEES, 1 quai Koch, BP61039, F-67070 Strasbourg, France Full list of author information is available at the end of the article
}

technological (Brilly and Polic 2005; Lowrey et al. 2007; Weinstein 1989). These studies conclude that informing the population of the risk they are exposed to should contribute to increase adoption of protection measures, to reduce the potential damages of disasters and should help to make the risks more acceptable for the society. In the case of natural hazards, the literature highlights that a link exists between preventive information and the behaviour of individuals during a crisis, even if the nature of this relation is constantly questioned (Brilly and Polic 2005; Cutter et al., 2003; Lindell and Barnes 1989). This study pursues an in-depth reflection on this issue, by focusing on the part of 
risk representation and the legitimacy of its management in individuals' behaviours.

For mud-flood prone areas, Heitz et al. (2009) have proven that information campaigns are useful to explain the processes of formation of a risk to the population. They have shown that (1) knowing the formation about the risk contributes to decrease the level of threat perceived by the individuals and (2) providing information can help increasing the implementation of individuals' protections and the modification of behaviours decided by the individuals. In their study on floods risks in Germany, Bubeck et al. (2012a, b) show that information can also encourage individuals to protect their private proprieties and modify their point of view on safety measures they can be implemented at the individual scale. Regarding this point, information could directly improve the adoption of appropriate behaviours in case of a disaster. But, Slovic (1986) shows that risk information may frighten the population by giving a lot of recommendations to individuals who are not necessarily in demand. Information on the damages can also "create extreme negative reactions in people because of the difficulty of appreciating the improbability of such extreme but imaginable consequences". The distinction between what is possible and what is probable represents the major issue. This author concludes that to have efficient information policies, the subjective judgements and representations of individuals have to be taken into account. The main issue is then to adapt the way information is provided to the population.

From this point of view, the perceived legitimacy of authorities disclosing information is another key issue in the adoption of the adapted risk behaviours by individuals (Ballantyne et al. 2000; Dahlstrom et al., 2012). Then, to compel the population to follow the authorities' recommendations and to adopt the appropriate behaviours in case of a disaster, the information should take into account the level of legitimacy they get for the authorities in charge of risk management (Cvetkovich 1999). The methods used in Social Sciences can then be useful in the understanding of behaviours and practices (Barberi et al. 2008; Bickerstaff 2004; Brilly and Polic 2005; Drori and Yuchtman-Yaar 2002; Drottz-Sjöberg 1993; Finlay and Fell 1997). They can be adapted to understand the attitudes for populations exposed to a major risk such as lahars. As other natural hazards such as volcanic eruptions, the consequences of lahars are unpredictable and are important both on the population and the infrastructures (Vargas Franco et al. 2010). In this context, the present contribution focuses on the assessment of subjective judgement of individuals (living in risk-prone areas) on natural hazards and disaster, in order to answer the main question: how can we qualify the link between representation, information and behaviours? Three hypotheses will be tested: (1) the lahars are a major issue for the population of Arequipa: this hypothesis will express the social representation of the lahars and compare this risk to other social issues; (2) the level of information on lahars (exposure, consequences and prevention) is linked to confidence and trust in the authorities that disclose this information: this hypothesis will test the strength of the relation between legitimacy in disclosing information and risk representation and the difference of legitimacy to different local/national authorities according to the individuals' socio-economic characteristics or to the precise knowledge of their missions in risk management; (3) the individuals who have been affected to lahars are more aware of their level of exposure and of the severity of lahars than those who did not experienced a lahar: this hypothesis will test the relation between experience and risk perception.

To answer these hypotheses, we analyse data gathered during surveys conducted in Arequipa (Peru). The methodology is based on 209 self-administrated questionnaires conducted in risk-prone areas and unexposed ones.

\section{The local context of the city of Arequipa: A lahars risk-prone area}

The city of Arequipa (South Peru) is located on the foot of El Misti volcano. The eruptive history of El Misti volcano has been studied by several authors (Bullard 1962; De Silva and Francis 1990; Thouret et al., 1999, b; Thouret et al. 2001; Thouret et al. 1995; Thouret et al., 1999, b; Pallares et al. 2015; Martelli 2011). Thouret et al. (2001) and De Silva and Francis (1990) confirm that "... the El Misti volcano is one of the seven [potentially] active volcanoes of the Central Andean volcanic zone of south Peru". Thouret et al. (1995) recount the history of Arequipa and its volcanic activity showing that the eruptive activity at El Misti represents a threat for the 750,000 inhabitants of Arequipa (Fig. 1). They estimate that at least 220,000 people in the surroundings of the city of Arequipa live at risk from pyroclastic flows, lahars and hyperconcentrated flash floods. Martelli (2011) summarized all lahars and flash foods events that occurred in Arequipa: between 1967 and 2001, 8 events have been identified. The last one occurred on March 2001 and caused floods (including significant debris), destroyed homes, roadways and bridges (Martelli 2011). Nagata (1999) proposed also a complete analysis of all the hyperconcentrated flash floods which occurred in Arequipa from the seventeenth Century until 1997. Lahars are "...a rapidly flowing mixture of rock debris and water (other than normal streamflow) from a volcano" (Smith and Fritz 1989). Lahars occur on and from volcanic slopes by incorporation of water, often after heavy rain events. As these sediment-laden flows can reach the lower slopes and valleys surrounding volcanoes, important damages occur in the cities located downslope. 


\section{EL MISTI HAZARD-ZONE MAP AND THE CITY OF AREQUIPA WITH PRINCIPAL ASSETS}

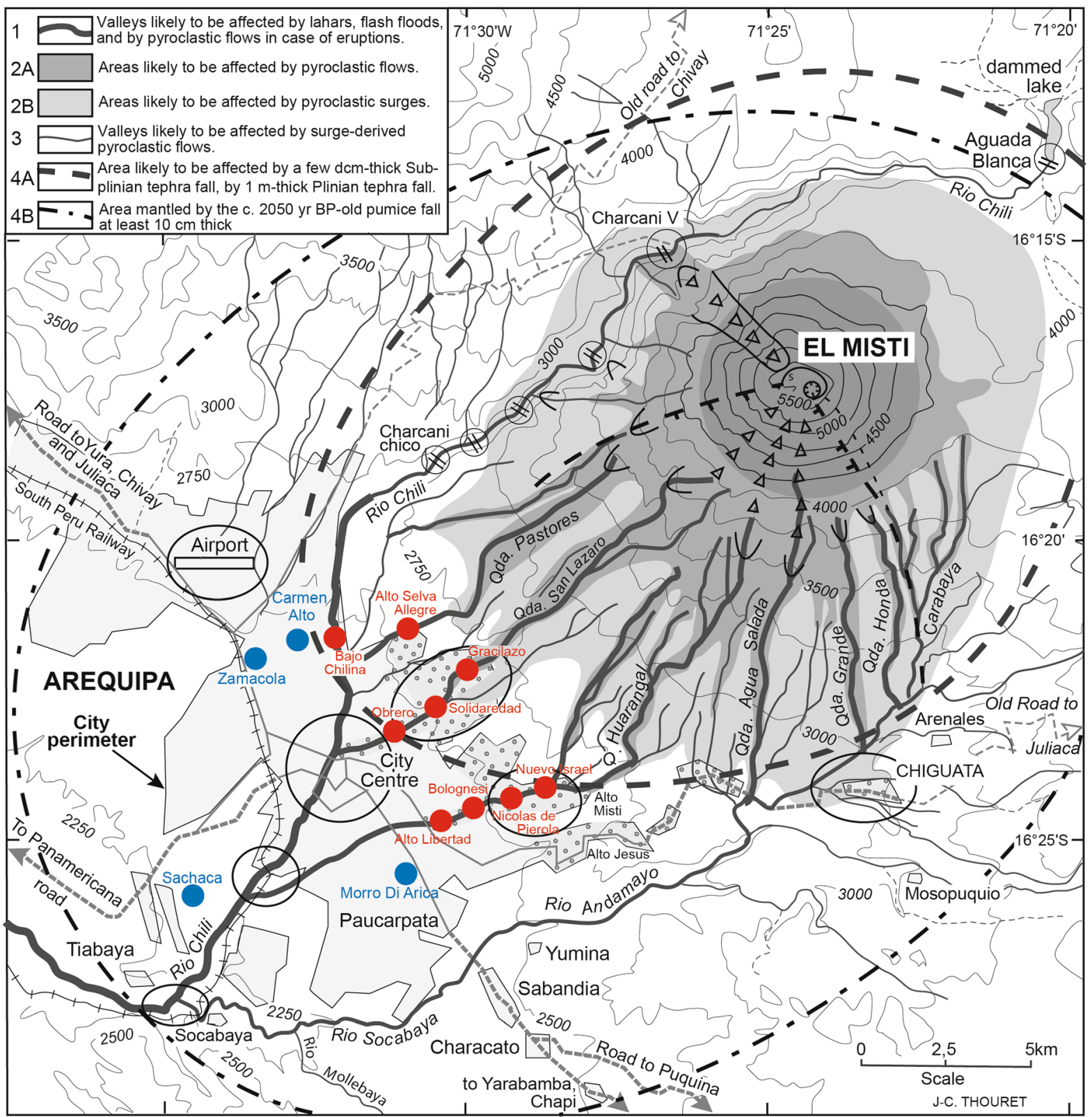

$5 \square$ Area probably hit by ballistic ejecta.

$6 \mathrm{~A} \longrightarrow$ Area likely to be affected by rockslides.

$6 \mathrm{~B} \sim \mathrm{T}$ Area liable to flank failure in case of large

6C $\Delta \triangle$ Steep slopes and channels swept by recent

74 Probable outreach of potential lava flows.

$8 \longrightarrow$ Seasonal streams potentially affected by
9 Principal valley channels and low terraces at risk in all cases.

$10 \quad \because \because$ Urban districts and suburbs at high risk, to be evacuated in $11 \mathrm{~A} \bigcirc$ Principal asset at risk in all cases.

$11 \mathrm{~B} O$ Secondary asset or asset at risk in the case of medium-sized

$12 \mathrm{~A}=\mathrm{P}$ Paved road usable for evacuation

$12 \mathrm{~B}$

Fig. 1 Location of the surveyed neighbourhoods in Arequipa on the hazard zone map (modified from Vargas Franco et al. 2010). In red, the neighbourhoods exposed to lahars/in blue, the neighbourhoods not exposed to lahars. Notes of caution: The entire area enclosed in the map is liable to tephra fall a few centimeters thick in case of Plinian eruptions, The map integrates seasonal variations of prevailing winds. The distribution of tephra therefore may vary from this map 
Knowing the vulnerability of the population exposed to lahar risks is one of the key issues in the decrease of the related damages, even if very few studies have focused on this point yet. Vargas Franco et al. (2010) gathered information on roads and bridges during their study on volcanic risk and mapping. Their preliminary observations show that "... these infrastructures are not only vulnerable to lahars, but in some cases, they can also contribute to increase the hazard levels due to the type of their design". The authors insist on the fact that the protections implemented on the slopes' rivers allowing to decrease the velocity of the lahars can also leads to produce other risks, such as floods or overflows in the surroundings by their inappropriate design. A complete study of the vulnerability in Arequipa has also be done by Martelli (2011).

\section{Methods}

To have a detailed knowledge of the individuals' representation of lahars risk, we set up a protocol of surveys based on questionnaires. Using questionnaire is common and proven method in risk representation studies (Smerecnik et al. 2012). The literature shows that having a better understanding of the risk representation of the population located in the risk-prone areas can be useful to determine the viability and the efficiency of a risk specific management (Bubeck et al., 2012, b; Cutter et al., 2000). The questionnaires can then help us gathering data on representation in the local context of Arequipa and to test if that kind of knowledge could useful to understand the observed behaviours and the risk management policies.

\section{Implementing questionnaires to understand the risk representation}

The use of questionnaires was motivated by the necessity (1) to understand the participants' representations (defined by Moscovici as "systems of values, ideas and practices with a two-fold function; first, to establish an order which will enable individuals to orientate themselves in their material and social world and to master it; secondly, to enable communication to take place amongst members of a community by providing them with a code for social exchange and code for naming and classifying unambiguously the various aspects of their world and their individual and group history" (in Wagner et al. 1999) and (2) to find the explanatory factors of these representations by datacrossing between the social indicators and the questioned behaviours (Rohrmann 2002). Questioning the individuals' practices allows us to analyse the intrinsic relations between a system of ranking of the individuals habits (dealing with the preferences in their daily behaviours), their social conditions (the social class, for example) and the distance to a source of risk (risk location and spatialisation by using its metric nearness, for instance (Bickerstaff and Walker 2001; Birkmann 2007; Blaikie et al. 1994; Brenot et al., 1998;
Brody et al., 2004; Paton et al. 2008; Rayner 1992; Renn 2004). Studying the behaviours introduces then the analyses of the "objective" sense that individuals give to their behaviours and habits by crossing them with social characteristics and data on the way individuals develop and involve a specific attitude. This approach leads then to distinguishing the "real" objects from the "built" objects according to the interests that the situation presents for the individuals (Slovic 2000; Slovic and Peters 2006; Weber and Hsee 2000).

In this context, the questionnaire used is based on a literature review of previous studies on risk perception (Barberi et al. 2008; Carlino et al., 2008; Haynes et al., 2008; Nathan 2009) and a detailed socio-economic analysis of the local context done in the framework of the Laharisks Program (Enjolras et al. 2012; Thouret et al. 2013). It allows us to choose the most relevant formulations adapted to the local context and cross our results with studies implemented in other social and cultural contexts to test their validity.

The objective of the questionnaire is to collect data to identify direct indicators (the personal feelings on social issues, for instance) and indirect ones (the socio-economic status of the respondents) which will directly influence the representation and the associated behaviours of individuals living close to lahars risk prone areas.

The questionnaire is organized around three main themes: the starting point is a general approach of the way surveyed people rank social issues (9 questions). Then, we focus our questions on natural hazards (issues, knowledge and known consequences) to end with lahars risk (10 questions). Socio-economic characteristics for each individual are also specified (living condition, salaries, profession - 6 questions).

The surveys take place in the following way. All the citizens of the 13 selected neighbourhoods of Arequipa have been informed of the survey (date and time of the survey) by the local councillor and have been called to participate on a voluntary basis. Groups of individuals (16 to 28 persons according to the sessions) have been constituted at the moment of the survey and have been invited in a public place where the whole survey is followed. All the respondents are identified by a code and are informed that their participation is anonymous. To fill in the questionnaire, the respondents have been helped (face to face) by local researchers.

\section{Population surveyed}

The population surveyed in this study was chosen in regard with their exposure to lahars (Fig. 1). 209 individuals (in 13 neighbourhoods of Arequipa) were surveyed in July 2010: 145 in lahars risk-prone areas and 64 in unexposed ones. In detail, the sampling counts $33 \%$ of men and $67 \%$ of women, which is not representative of the Peruvian 
population (49\% women and 52\% men - INEI 2013). The majority of the sampling is owner (76\%) and lives with their family (89\% - parents, children, grandparents or uncles/ aunts). At the national level, the percentage of owner is 72\%: our sampling is close to the national level (Instituto Nacionale de Estadistica E Informatica (INEI) 2013). The level of education is very low: only $40 \%$ of the respondents declare that they were at school (1st and 2nd degree) and $30 \%$ of the sample does not work at the moment of the survey. The census in Arequipa counts that $42 \%$ of the inhabitants have been at school until the 2nd degree and $30 \%$ of the population is inactive. The mean salary is less than 300 Soles per month for $40 \%$ of the sampled population, which reveals an extreme poverty of the respondents (the mean salary is 1435 Soles per month (Instituto Nacionale de Estadistica E Informatica (INEI) 2013).

\section{Results and discussion: Relations between risk, social concerns, experience and representation}

We focus our results on our three main hypotheses: (1) the lahars are a major issue for the population of Arequipa; (2) the level of information on lahars (exposure, consequences and prevention) is linked to confidence and trust in the authorities that disclose this information; (3) the individuals who have been affected to lahars are more aware of their level of exposure and of the severity of lahars than those who did not experienced a lahar. All our results have been analysed using statistics test such as the $\mathrm{Chi}^{2}$ test and Fisher test to measure the strength of our analyses. The first results deal with the position of lahars risk among other risks and concerns. Then, we analyse the place of risk prevention, information and confidence in the implementation of preventive measures and finally, we question the place of the experience in the risk representation.
The lahars compared to main social issues and other kind of natural hazards

Our results show that the respondents estimate that natural hazards are more important that the corruption and the fact of living with less than 5 Soles per day (Fig. 2). First of all, this ranking can be explained by an awareness of a corruptive system that is daily mentioned in the national and local newspapers and against which the population cannot fight. The neighbourhood of residence is highly significant in this result: the inhabitants of San Martin located on the East part of Arequipa are those who think the most that natural hazards are more important than living with less than of 5 Soles per day $\left[\mathrm{Chi}^{2}(55,15) ; p=.01 ; \mathrm{df}=34\right]$. This neighbourhood is located in one of the valley (quebradas) which suffer the most of lahars. Despite the fact that corruption is less important than natural hazards, urban insecurity and urban violence (designed as "Violence") are perceived as very important. The level of education is highly significant in this result: individuals who think that the violence is more important than lahars have been at school until the first degree (Primaria). On the contrary, the individuals with a higher level of education (University degree) think that an exposure to lahars is more important $\left[\mathrm{Chi}^{2}(16,41) ; p=.04 ; \mathrm{df}=8\right]$. It is worth mentioning that the population with a high level of education is not exposed to the same level of violence, because of their living condition and social status. Providing a good healthcare system, good sanitary conditions and a good education system to children are also considered as more important than exposure to lahars risk. Looking for a distinction between exposed and unexposed areas, we split our sampling in two groups (red and blue areas in Fig.1): the results show that there are some exposure effects in the ranking of environmental issues among other social concerns. The individuals living in areas at risk (in red - Fig. 1) are those who think the most that

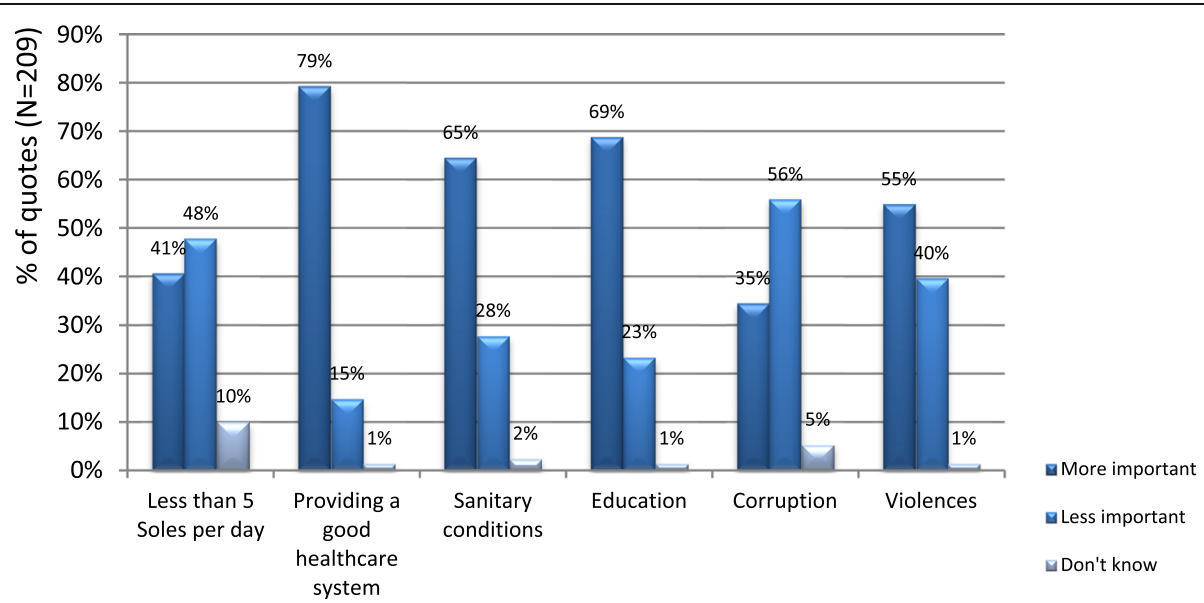

Fig. 2 Classification of the answers to the question: "Can you indicate the importance (more or less important) that you lend to these social concerns in comparison with risks such as lahars, earthquakes, volcanic eruption?" 
providing a good education system is more important than the exposure to lahars [F $(4,16) ; p<.01]$. In the same way, the individuals who think that corruption is more important than lahars are those living in the neighbourhood of Nicolas de Pierola one of the most exposed area to lahars in the region $\left[\mathrm{Chi}^{2}(51,26) ; p=.03 ; \mathrm{df}=34\right]$. This distinction is also true for the health risk. The inhabitants of Nuevo Israel, one of the poorest municipality of Arequipa, think most that the exposure to lahars is less important than health issues $\left[\mathrm{Chi}^{2}=(67,95) ; p=<.01\right.$; $\left.\mathrm{df}=34\right]$.

Others social characteristics are significant in this evaluation of lahars risk: individuals who have experienced once a time lahars estimate that this exposure is less important than the other social issues we proposed $\left[\mathrm{Chi}^{2}=(6,06) ; p=.05 ; \mathrm{df}=2\right]$. In the same way, having children is highly significant: inhabitants having at least one child estimate that lahar risk is less important than all the other social issues together $\left[\mathrm{Chi}^{2}=(17,17) ; p=<.01\right.$; $\mathrm{df}=2]$. More precisely, providing a good education system is more important than the exposure to lahars risk for them $\left[\mathrm{Chi}^{2}=(7,29) ; p=.03 ; \mathrm{df}=2\right]$.

The type of habitation is also a significant factor. For instance, the owners think more than the tenants or those living in their family that the exposure to health risk is more important than lahars $\left[\mathrm{Chi}^{2}=(10,10) ; p=.04\right.$; $\mathrm{df}=4]$. This result could be explained by the economic load that represents the credit purchase for a house.

Focusing on natural hazards, volcanic eruption is the most often indicated (Fig. 3), followed by earthquakes and lahars and the consequences of drought in third position. It is worth mentioning that respondents spontaneously quote the volcanic eruptions. They live close to the El Misti volcano, which is clearly visible in the surroundings of the surveyed people: Moreover, the Civil Protection (Defensa Civil) managed some emergency exercises among the communities since the 1980's to adapt the individuals' behaviours in case of a volcanic eruption. Information to children is directly provided at schools or by using internet (http://www.indeci.gob.pe or http://www.ingemmet. gob.pe for access to educational supports). Many leaflets of prevention and information are delivered in the concerned municipalities, pointing out the security instructions in case of volcanic risk and seismic risk (quoted in 2nd position in Fig. 3). Seismic risk is also a reality felt daily by the population explaining their awareness to this kind of risk (daily tremors are recorded in the Arequipa surroundings). Lahars risk is quoted in third position as well as the consequences of drought. The importance of the earthquakes and the proximity of the El Misti volcano in the region get the upper hand on all the others environmental issues. The fact that the lahars are quoted in third position shows all the same that their occurrences represent a real risk for the population. The place where the inhabitants are living is highly significant in this classification: the inhabitants of Alto Selva Alegre (Fig. 1) are those who quote the most the volcanic risk in first position. The inhabitants of Nuevo Israel are those quoting the most the lahars in first position and for the volcanic risk, the inhabitants of Carmen Alto (not exposed to lahars - Fig. 1) are those quoting the most this risk in first position $\left[\mathrm{Chi}^{2}=(158,15) ; p=<.01 ; \mathrm{df}=85\right]$.

In this classification, personal experience is also a major factor: inhabitants who have experienced a lahar are those who quote this risk in first. Inhabitants who declare not having experienced a lahar, will quote the seismic risk in first position $\left[\mathrm{Chi}^{2}=(23,26) ; p=<.01\right.$; $\mathrm{df}=5]$. The level of education explains also this classification. Our results show that the inhabitants with a high level of education (University degree) will quote the volcanic risk in first position and those having a lower level of education (first degree - Primaria) will quote the lahars risk in first $\left[\mathrm{Chi}^{2}=(42,94) ; p=<.01 ; \mathrm{df}=20\right]$. This result can easily be explained by the repartition of the population in the city of Arequipa: the people with a low level of education are mainly living in the valleys

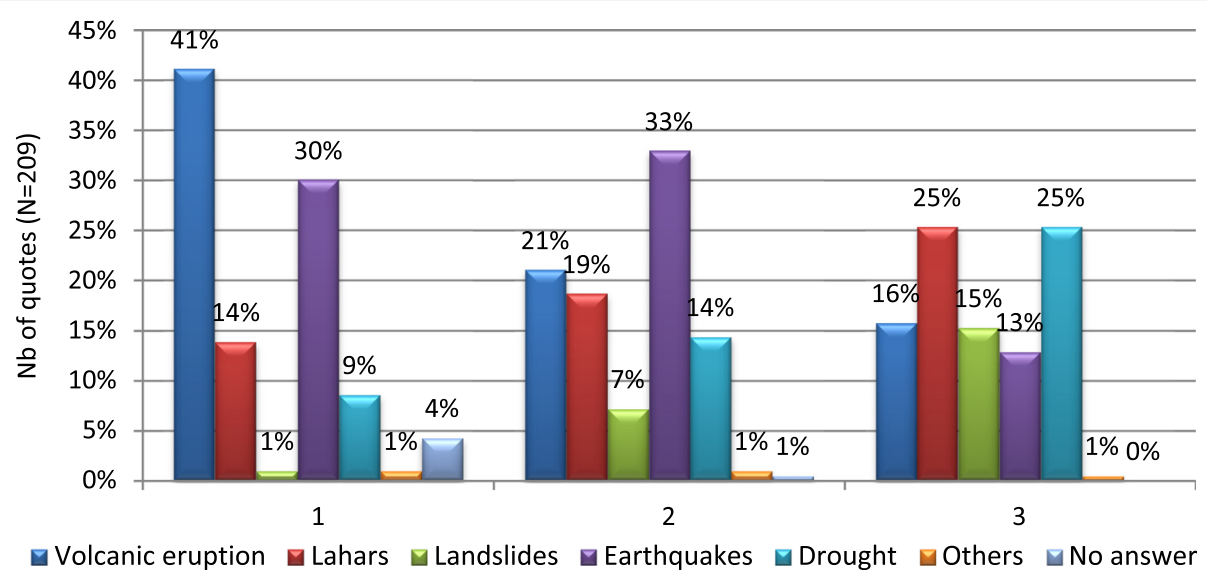

Fig. 3 Ranking of the first 3 answers to the question: "Can you rank these natural hazards from the more important to the less important for you?" 
(quebradas) contrary to the population with a higher level of education. Last point, having children influence the ranking: inhabitants with children will mostly rank the volcanic risk in first position. Those who declare not having any child, rank the dough in first position $\left[\mathrm{Chi}^{2}=(15,29) ; \quad p=<.01 ; \mathrm{df}=5\right]$. This result can be explained by all the information that is disclosed to children at school to inform on seismic risk exposure.

\section{How can we influence the implementation of preventive measures? Trust, information and confidence}

The results show that respondents endow legitimacy in risk reduction (61\%) to the Civil Protection (Defensa Civil) in charge of the management of risk in the city (Fig. 4) followed by the local authorities (18\%) and the media $(10 \%)$. The inhabitants with a high level of education (University degree) are those who endow the more legitimacy to the Civil Protection. On the contrary, inhabitant with a lower level of education (1st degree) will estimate that the local authorities are legitimate in risk prevention policies $\left[\mathrm{Chi}^{2}=(92,77) ; p=<.01 ; \mathrm{df}=20\right]$. Although the Defensa Civil provides information and get involved in the formation of the population in case of natural hazards, $65 \%$ of the respondents $(N=209)$ consider that they are not sufficiently informed on the behaviours to adopt in case of a disaster. Women estimate more than men that they are not enough informed on lahars risks $\left[\mathrm{Chi}^{2}=(12,66)\right.$; $p=<.01 ; \mathrm{df}=1]$. More precisely, when we asked what kind of solution could be implemented to decrease the damages due to natural disasters, the respondents mentioned (50\%) a better communication by using prevention and information campaigns for the inhabitants in risk prone areas (Fig. 5). The second point would be a better legislation dealing with the urban planning regulation (22\%). In our sampling, three main parameters are influencing this result: first, the experience. Inhabitants who have been affected by a lahars, estimate more than the others that it is important to protect the urban areas $\left[\mathrm{Chi}^{2}=(20,47) ; p=.03 ; \mathrm{df}=10\right]$. Secondly: the level of education. The inhabitants with a high degree of education (University degree) think more than the others that it is necessary to implement information and prevention campaigns on lahars risk exposure. The inhabitants with a lower level of education think that the first solution is to protect the urban areas exposed to this kind of risk $\left[\mathrm{Chi}^{2}=(34,61) ; p=<.01 ; \mathrm{df}=8\right]$. Third parameter: the inhabitants who have children think more than the others that the first action is to protect the exposed areas $\left[\mathrm{Chi}^{2}=(10,45) ; p=<.01 ; \mathrm{df}=2\right]$.

To understand all these results, we have to specify that, in the risk prone areas, plots are not subject to homeownership and the poorest part of the population can live in these vulnerable areas without any control. It leads to important expectations towards authorities' action in decreasing their vulnerability (59\% - Fig 6) and to a weak implication of the respondents in the adoption of individual initiatives to protect themselves (24\% - Fig. 6).

\section{The prevailing part of experienced events in the level of risk perception}

From the sample, $40 \%$ of the surveyed population has experienced a lahar at least one time in their life $(60 \%$ did not). By asking each individual to estimate on a 0 to 10 points scale the level of threat that represents a lahar, we analyse the importance of the experience on the level of risk representation. For these analyses, we focus our sampling on the people living in exposed areas. The lahars represent a threat estimated to $\mu=6,5 / 10(\sigma=2,9)$ for

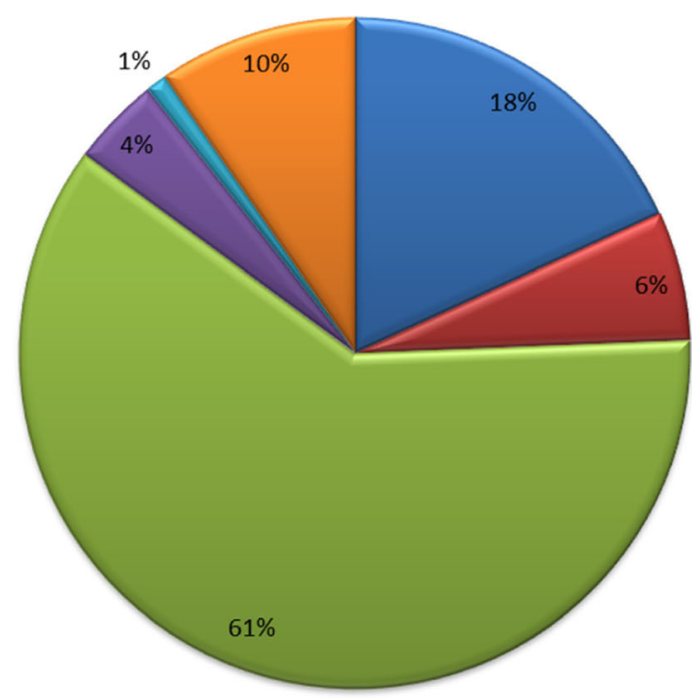

Local authorities

Scientists

$\square$ Civil Protection

Regional authorities

Other

Medias

Fig. 4 Answer to the question: "Which authority do you trust in for the information on the lahars you receive?" ( $N=209)$ 


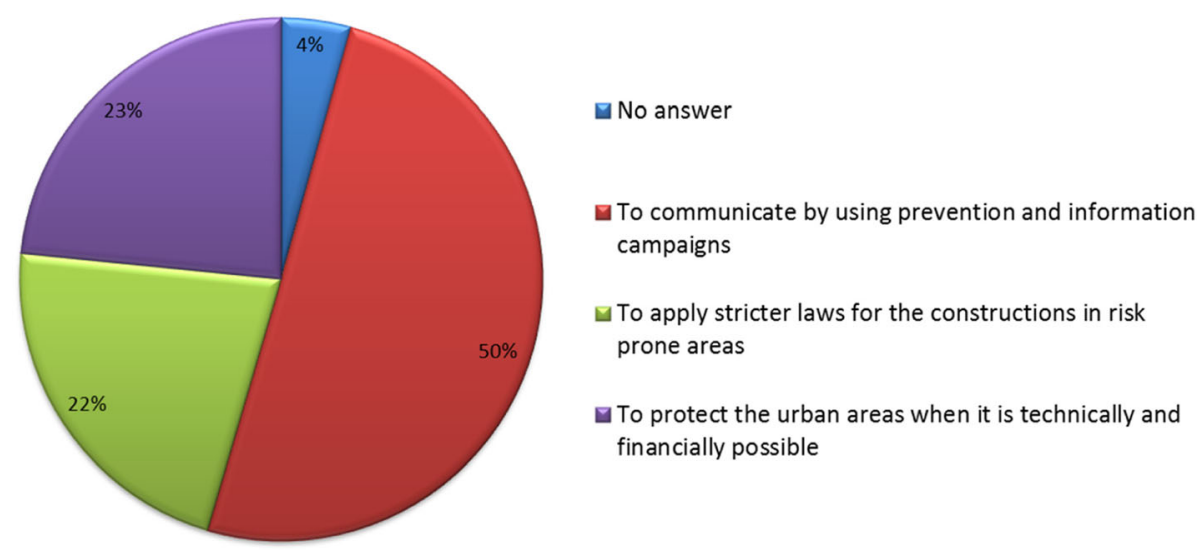

Fig. 5 Answer to the question: "To better cope with the risk of lahars, we have to ...?" ( $N=209)$

individuals living in exposed areas but who have not experienced a lahar in their lives (Fig. 7).

By comparing these results to those of individuals who have experienced lahars (Fig. 8), we can underline that the mean is higher $(\mu=7,8 ; \sigma=2,2)$. This result is not surprising: people have suffered from damages due to lahars and then they link their feeling of threat to their experience. Our results show that: (1) there is a high significant strength between the level of threat and the living area: the inhabitants of Solidaredad perceive a high level of threat, contrary to those living in Sachaca $[\mathrm{F}=(2,10)$; $p=.06]$; (2) experience of lahars is a strong predictor of a high perception of threat $[\mathrm{F}=(9,87) ; p=<.01]$.

We test the link between the experience of a lahar and the protection measures individuals could implement (Fig. 9). We have split the sampling into 2 groups between the inhabitants who suffered from damages due to lahars and those who did not. Individuals who have never been exposed to a lahar think that we cannot do anything or that the local authorities are in charge of their protection (respectively 69\% and 62\%). People who have experienced at least one lahar in their life think that they could implement better individuals' protections measures to decrease the damages they could suffer in the future (53\%). We can see that the experience can impact the representation of their own responsibility regarding to their level of protection or their will to implement such measures. This result is interesting because it reveals the level of responsibility individuals can perceive after a lahar event and national authorities in charge of the risk management could pay attention to this in order to implement better information campaigns after a disaster.

\section{Conclusion}

This study assessed the role of risk representation in the risk behaviours' characteristics, and the present work has tested three main hypotheses.

(1)The lahars are a major issue for the population of Arequipa. Our results show that the environmental issues are not significantly quoted by individuals among other social concerns. Indeed the population of Arequipa seems more concerned by issues as providing a good healthcare system, a good education

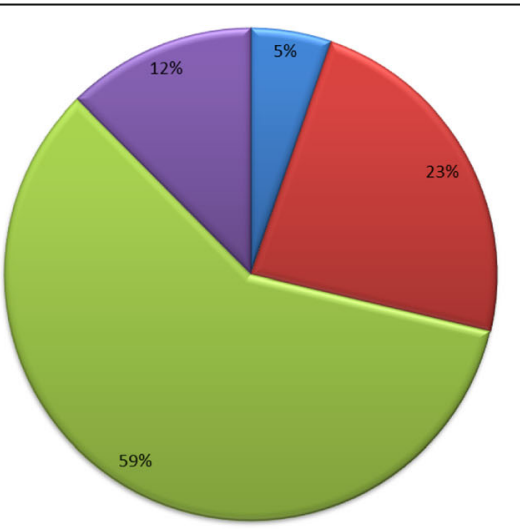

No answer

The individuals should protect themselves

$\square$ The local authorities should control the land use planning to protect the population

$\square$ We can make nothing to it

Fig. 6 Answer to the question: "Here are several suggestions. Which is the one that is closest to your opinion about lahars?" ( $N=209)$ 


\begin{tabular}{|l|l|}
\hline Nb. of observations & 72 \\
\hline Minimum & 0 \\
\hline Maximum & 10 \\
\hline Median & 7.130 \\
\hline Mean & 6.55 \\
\hline Variance (n-1) & 8.62 \\
\hline Std-deviation (n-1) & 2.94 \\
\hline
\end{tabular}
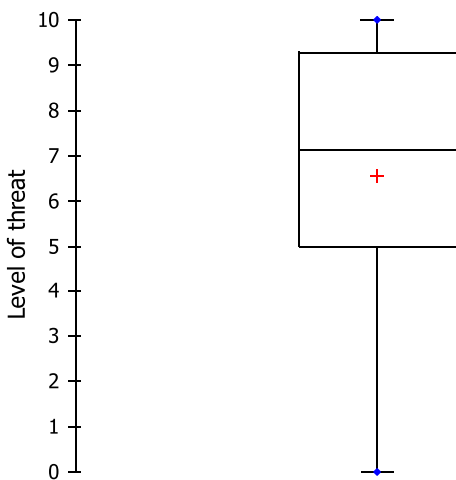

Fig. 7 Answer to the question: "On this scale, you can set the level of threat that the risks of lahars represent to you?" $(0=$ no threat, $10=a$ great threat)/Inexperienced people in risk prone areas $(n=72)$

system or a high level of security in the city. This kind of result is common in risk representation studies mainly in European countries as mentioned in Dietz et al. (2002) and Duflos and Hatchuel (2004). People are more concerned by every day issues and the last big lahars event was in 2001 (9 years before our survey). People don't carry on the memory of past events, as shown in other studies on memory and risk exposure (Tidball et al. 2010; Dominey-Howes and MinosMinopoulos 2004). It seems that the proximity to a source of risk can slightly influence this representation. Indeed, our results show that the proximity of El Misti volcano influence the ranking of natural hazards: Zonabend (1989) analyses also that the fact that individuals can see the risk source can increase their representation of this risk. Added to the proximity of the risk source, the experience (in our case of lahars) is also a maj Cohen et al., 2008 or predictor of high risk awareness in comparison with other social issues. Other studies prove also that the experience is essential in risk representation

(; Grothmann and Reusswig 2006; Zhai et al. 2006).
(2) The level of information on lahars (exposure, consequences and prevention) is linked to confidence and trust in the authorities that disclose this information. In Arequipa, the legitimacy to inform on lahars risk is given by the individuals to national authorities and to Civil Protection. As in other studies, the national level is mainly quoted as a trustful stakeholder (Bradbury et al., 1999; Cvetkovich 1999; Earle and Cvetkovich 1999). In our study, no socio-economic characteristics are highly significant to clarify if there is a link between a level of education, conditions of living or a good knowledge of the missions of authorities in charge of risk management to explain why individuals provide legitimacy to one specific stakeholder. To go further in this analyze, we should question the individuals on their main representative on risk issues.

(3) The individuals who have been affected to lahars are more aware of their level of exposure and of the severity of lahars than those who did not experienced a lahar The experience takes a prevailing part in the implementation of individuals'

\begin{tabular}{|l|l|}
\hline Nb. of observations & 72 \\
\hline Minimum & 0 \\
\hline Maximum & 10 \\
\hline Median & 6.95 \\
\hline Mean & 7.87 \\
\hline Variance (n-1) & 5.08 \\
\hline Std-deviation (n-1) & 2.25 \\
\hline
\end{tabular}
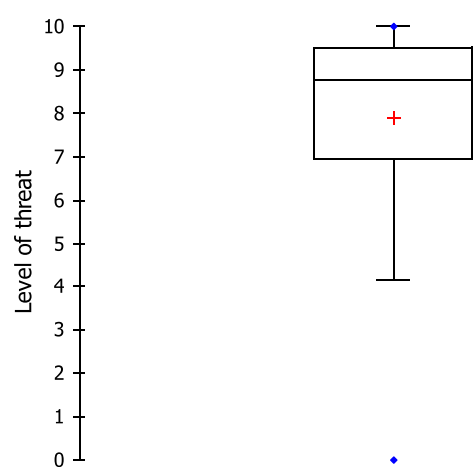

Fig. 8 Answer to the question: "On this scale, you can set the level of threat that the risks of lahars represent to you?" $(0=$ no threat, $10=a$ great threat)/Experienced people in risk prone areas $(n=72)$ 


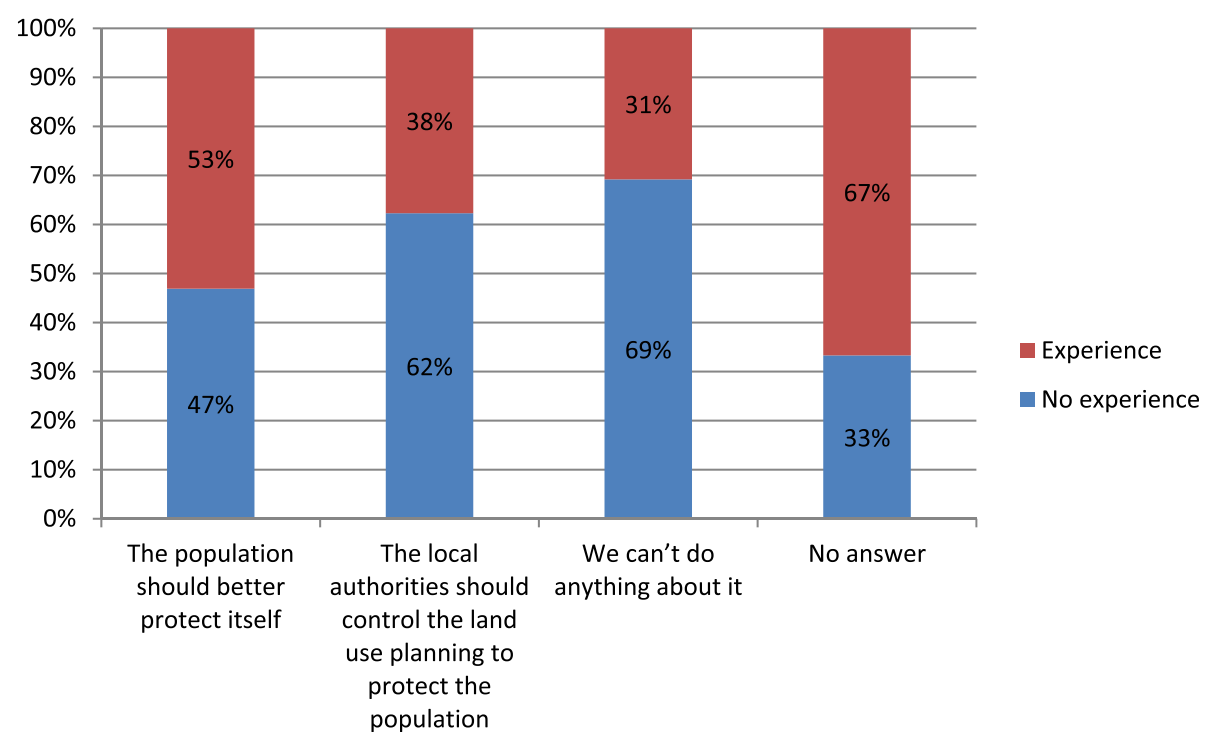

Fig. 9 Answer to the question: "Here are several suggestions. Which is the one that is closest to your opinion about lahars?" (experience in lahars $N=82$ / no experience in lahars $N=118$ - all areas) $-\left[\right.$ Chi $\left.{ }^{2}=(5,44) ; p=.14 ; \mathrm{df}=3\right]$

protection measures. The inhabitants who were affected by lahars show a higher level of risk perception (threat) than other inhabitants. Heitz et al. (2009) show similar results for muddy floods but, as in this case study, the differences are not highly significant. The proximity of the respondents to individuals who have experienced lahars and declared damages can explain the high mean of perceived threat by inhabitants who were not affected. The "neighbourhood" effect explains that some individuals are afraid by a risk even if they are not directly concerned but just by seeing the damaged effects.

This work sets on some grounds for thoughts. Concerning the sampling method for the respondents' selection: we based our discrimination between areas characterized by various exposures to risk. These slight differences did not appear in our sample. To the same degree, it is impossible to spatialize perception data in reason of the limited number of respondents for each area (between 16 and 24 respondents by community) as well as in reason of the experimentation method (face to face in the same room). This distinction between the areas we proposed in the present study remains, by then, rather summary and do not allow to take in account social and cultural aspects inherent to each community that might play a role on the risk representations. Concerning the methodology, we can feature the current debate on the use of questionnaires to characterize behaviours. Indeed, the first hiatus lays in the technique itself: are we assured that the well thought out questions expressed by the researcher is caught (understood) in the same way by the respondent? This uncertainty leads to a repositioning of the debate on the validity of the data collected using a declarative method (even if validation techniques in the survey are able to reduce the noise due to these lacks of understanding and to control the coherence of the respondents). The second methodological hiatus is related to the relation that we establish between an answer to a question and a "real" or "observed" behaviour. This link is largely debated in the literature highlighting the fact that all statements don't reflect real behaviours.

Finally, scientific perspectives can be highlighted. Among others, we need to pursue our work to better understand the impact of the preventive information on the behaviours observed when a disaster occurs. One of this work's prospects corresponds to the joint application of two methodologies to evaluate risk perception. The present survey has been conducted in the framework of an interdisciplinary work realized with experimentalist economists (Bchir and Willinger 2013; Heitz et al., 2012). The purpose is to link declarative data collected though questionnaires, to revealed measurements obtained thanks to the experimental protocols. The use of these two methods would allow reducing biases due to the subjectivity of the answers collected with the questionnaires, by an inspection based on individuals' behaviours during experimental phases.

\section{Acknowledgements}

The authors acknowledge the Laharisk Project (French Research Funding (ANR) - Coord. JC. Thouret, Clermont-Ferrand University) for the financial support necessary for the implementation of the survey. The authors acknowledge Prof. M. Willinger, Dr. M.A. Bchir and Prof. G. Enjolras for their collaboration during the design of the surveys' protocol and during the implementation of the surveys in Arequipa. The authors acknowledge Elio Orlando Bazan Huamaní, José Delfín Cáceres Martínez, José Carlos Quispe Barreto, Pablo Ernesto Peña Meza, Sofia Vargas Romero and Noe Felipe Coaguila for their collaboration during the implementation of the surveys in Arequipa. 


\section{Availability of data and materials}

Data will not be shared: all the analyses have not been published for the moment.

\section{Authors' contributions}

Carine Heitz participates at the implementation of the surveys (design and sampling frame/implementation in Arequipa) and analyses all the data. Carine Heitz writes this manuscript.

Miriam Nagata Shimabuku participates at the implementation of the surveys in Arequipa and manages the meetings with the local stakeholders of all the neighbourhoods that were surveyed. Miriam Nagata Shimabuku is also our first representative in Arequipa and contacts the Peruvian researchers in Arequipa and Lima involved in the project. Both authors read and approved the final manuscript.

\section{Funding}

The study was funded by the French Research Funding (ANR) - Laharisk 09-Risk-005.

\section{Authors' information}

C.H. is Geographer, specialized in risk representation and attitudes, researcher at IRSTEA (National Institut in Environmental Studies) and ENGEES (National School for Water and Environmental Engineering).

M.N.S. is PhD student in Geography, graduated of a Master in Geology and

Professor at the Pontificia Universidad Católica del Perú.

\section{Competing interests}

The authors declare that they have no competing interests.

\section{Publisher's Note}

Springer Nature remains neutral with regard to jurisdictional claims in published maps and institutional affiliations.

\section{Author details}

'Irstea, UMR GESTE, ENGEES, 1 quai Koch, BP61039, F-67070 Strasbourg, France.

${ }^{2}$ Departamento de Humanidades, Centro de Investigación en Geografía Aplicada, Pontificia Universidad Católica del Perú, Av. Universitaria №, 1801 Lima, San Miguel, Peru.

\section{Received: 6 December 2017 Accepted: 11 December 2017}

Published online: 29 December 2017

\section{References}

Ballantyne, M., D. Paton, D. Johnston, M. Kozuch, and M. Daly. 2000. Information on volcanic and earthquake hazards: The impact on awareness and preparation, 2000/2: Institute of Geological \& nuclear sciences limited.

Barberi, F., M.S. Davis, R. Isaia, R. Nave, and T. Ricci. 2008. Volcanic risk perception in the Vesuvius population. Journal of Volcanology and Geothermal Research 172: 244-258.

Bchir, M. A., and M. Willinger. 2013. Does the exposure to natural hazards affect risk and time preferences? Some insights from a field experiment in Perú. Working paper LAMETA, DR 2013-4, 29 p.

Bickerstaff, K. 2004. Risk perception research: Socio-cultural perspectives on the public experience of air pollution. Environment International 30 (6): 827.

Bickerstaff, K., and G. Walker. 2001. Public understanding of air pollution: The "localisation" of environmental risk. Global Environmental Change 11: 135-145.

Birkmann, J. 2007. Risk and vulnerability indicators at different scales: Applicability, usefulness and policy implications. Environmental Hazards 7 (1): 20-31.

Blaikie, P., T. Cannon, I. Davis, and B. Wisner. 1994. At risk: Natural hazards, people's vulnerability, and disasters. London and New York: Routledge Publishers.

Bradbury, J.A., K.M. Branch, and W. Focht. 1999. Trust and public participation in risk policy issues. In Social trust and the management of risk, ed. G. Cvetkovich and R.E. Lofstedt, 117-127 Earthscan.

Brenot, J., S. Bonnefous, and C. Marris. 1998. Testing the cultural theory of risk in France. Risk Analysis 18 (6): 729-739.

Brilly, M., and M. Polic. 2005. Public perception of flood risks, flood forecasting and mitigation. Natural Hazards and Earth System Sciences 5 (3): 345-355.

Brody, S.D., B.M. Peck, and W.E. Highfield. 2004. Examining localized pattern of air quality perception in Texas: A spatial and statistical analysis. Risk Analysis 24 (1): $1561-1573$.
Bubeck, P., W.J.W. Botzen, and J.C.J.H. Aerts. 2012a. A review of risk perceptions and other factors that influence flood mitigation behavior. Risk Analysis 32 (9): 1481-1495.

Bubeck, P., W.J.W. Botzen, H. Kreibich, and J.C.J.H. Aerts. 2012b. Long-term development and effectiveness of private flood mitigation measures: An analysis for the German part of the river Rhine. Natural Hazards and Earth System Sciences 12: 3507-3518.

Bullard, F.M. 1962. Volcanoes of southern Peru. Bulletin of Volcanology 24: 443-453.

Carlino, S., R. Somma, and G.C. Mayberry. 2008. Volcanic risk perception of young people in the urban areas of Vesuvius: Comparisons with other volcanic areas and implications for emergency management. Journal of Volcanology and Geothermal Research 172: 229-243.

Cohen, M., J. Etner, and M. Jeleva. 2008. Dynamic decision making when risk perception depends on past experience. Theory and Decision 64 (2-3): 173-192.

Cutter, S.L., B.J. Boruff, and W.L. Shirley. 2003. Social vulnerability to environmental hazards. Social Science Quarterly 84 (2): 242-261.

Cutter, S.L., J.T. Mitchell, and M.S. Scott. 2000. Revealing the vulnerability of people and places: A case study of Georgetown country, South Carolina. Annals of the Association of American Geographers 90 (4): 713-737.

Cvetkovich, G. 1999. The attribution of social trust. In Social trust and the management of risk, ed. G. Cvetkovich and R.E. Lofstedt, 53-61 Earthscan.

Dahlstrom, M.F., A. Dudo, and D. Brossard. 2012. Precision of information, sensational information, and self-efficacy information as message-level variables affecting risk perceptions. Risk Analysis 32 (1): 155-165.

De Silva, S.L., and P.W. Francis. 1990. Active and potentially active volcanoes of southern Peru - observations using Landsat thematic Mapper and space shuttle imagery. Bulletin of Volcanology 52: 286-301.

Dietz, T., L. Kalof, and P.C. Stern. 2002. Gender, values, and environmentalism. Social Science Quarterly 83 (1): 353-364.

Dominey-Howes, D., and D. Minos-Minopoulos. 2004. Perceptions of hazard and risk on Santorini. Journal of Volcanology and Geothermal Research 137: 285-310.

Drori, I., and E. Yuchtman-Yaar. 2002. Environmental vulnerability in public perceptions and attitudes: The case of Israel's urban centers. Social Science Quarterly 83 (1): 53-63.

Drottz-Sjöberg, B. M. 1993. Risk perceptions related to varied frames of reference. Paper read at SRA Europe Third Conference. Risk analysis: underlying rationales, at Paris.

Duflos, C., and G. Hatchuel. 2004. Opinions sur les catastrophes naturelles, le développement durable et l'environnement au début 2004, 84: CREDOC.

Earle, T. C., and G. Cvetkovich. 1999. Social trust and culture in risk management. In Social trust and the management of risk, eds. G. Cvetkovich and R. E. Lofstedt, 9-21: Earthscan.

Enjolras, G., R. Kast, J.-C. Thouret, M. Nagata, B. Prihatminingtyas, and J.A.L. Uchuchoque. 2012. Managing flood hazard and risk in a changing climate the Indonesian and Peruvian experiences. In World congress on water climate and energy.

Finlay, P.J., and R. Fell. 1997. Landslides: Risk perception and acceptance. Canadian Geotechnical Journal 34: 169-188.

Grothmann, T., and F. Reusswig. 2006. People at risk of flooding: Why some residents take precautionary action while others do not. Natural Hazards 38 (1-2): 101-120.

Haynes, K., J. Barclay, and N. Pidgeon. 2008. Whose reality counts? Factors affecting the perception of volcanic risk. Journal of Volcanology and Geothermal Research 172: 259-272.

Heitz, C., M. Bchir, and M. Willinger. 2012. Does exposure to lahars risk affect people's risk-preferences and other attitudes? Field data from incentivized experiments and surveys in Arequipa-Peru. Paper read at EGU General Assembly Conference Abstracts.

Heitz, C., S. Spaeter, A.-V. Auzet, and S. Glatron. 2009. Local stakeholders' perception of muddy flood risk and implications for management approaches: A case study in Alsace (France). Land Use Policy 26 (2):224-234

Instituto Nacionale de Estadistica E Informatica (INEI). 2013. Condiciones de Vida en el Peru, 69: Instituto Nacionale de Estadistica E Informatica.

Joffe, H. 2003. Risk: From perception to social representation. The British Journal of Social Psychology 42: 55

Lindell, M.K., and V.E. Barnes. 1989. Protective response to technological emergency: Risk perception and behavioral intention. Journal of Safety Research 20 (1): 45.

Lowrey, W., W. Evans, K. Gower, J. Robinson, P. Ginter, L. McCormick, and M. Abdolrasulnia. 2007. Effective media communication of disasters: Pressing problems and recommendations. BMC Public Health 7 (1): 97. 
Martelli, K. 2011. The physical vulnerability of urban areas facing the threat of inundation from lahars and flash floods : application to the case study of Arequipa, Peru, Université Blaise Pascal - Clermont-Ferrand II.

Nagata, M. 1999. Una introduccion a las inundaciones en el area urbana de Arequipa, Informe sobre las Torrenteras en Arequipa, 99: INDECI-IGP-ORSTOM

Nathan, F. 2009. Disaster risk perception of people exposed: Are we asking the right questions? In Psychology of risk perception, ed. J.G. Lavino and R.B. Neumann, vol. 12. New-York: Nova Science Publishers.

November, V., and Y. Leanza. 2016. Risk, disaster and crisis reduction. Springer.

Pallares, C., D. Fabre, J.-C. Thouret, C. Bacconnet, J.A. Charca-Chura, K. Martelli, A. Talon, and C. Yanqui-Murillo. 2015. Geological and geotechnical characteristics of recent lahar deposits from el Misti volcano in the city area of Arequipa, South Peru. Geotechnical and Geological Engineering 33 (3): 641-660.

Paton, D., L. Smith, M. Daly, and D. Johnston. 2008. Risk perception and volcanic hazard mitigation: Individual and social perspectives. Journal of Volcanology and Geothermal Research 172: 179-188.

Paton, D., L. Smith, and D. Johnston. 2000. Volcanic hazards: Risk perception and preparedness. New Zealand Journal of Psychology 9 (2): 86-91.

Perry, R.W., and M.K. Lindell. 2008. Volcanic risk perception and adjustement in a multi-hazard environment. Journal of Volcanology and Geothermal Research 172: $170-178$.

Rayner, S. 1992. Cultural theory and risk perception. In Social theories of risk, ed. S. Krimsky and D. Golding, 83-115. Praeger.

Renn, O. 2004. Perception of risks. The Geneva Paper on Risk and Insurance 29 (1): 102-114.

Rohrmann, B. 2002. Risk attitude scales: Concepts and questionnaires, 20: University of Melbourne, Australia.

Sjöberg, L. 2000. Factors in risk perception. Risk Analysis 20 (1): 1-11.

Slovic, P. 1986. Informing and educating the public about risk. Risk Analysis 6 (4): 403-415.

Slovic, P. ed. 2000. The perception of risk: Earthscan.

Slovic, P., M.L. Finucane, E. Peters, and D.G. MacGregor. 2004. Risk as analysis and risk as feelings: Some thoughts about affect, reason, risk, and rationality. Risk Analysis 24 (2): 311-322.

Slovic, P., and E. Peters. 2006. Risk perception and affect. Current Directions in Psychological Science 15 (6): 322-325.

Smerecnik, C.M.R., I. Mesters, M.J.J.M. Candel, H. De Vries, and N.K. De Vries. 2012. Risk perception and information processing: The development and validation of a questionnaire to assess self-reported information processing. Risk Analysis 32 (1): 54-66.

Smith, G.A., and W.J. Fritz. 1989. Penrose conference report: Volcanic influences on terrestrial sedimentation. Geology 17: 375-376.

Thouret, J.C., J. Davila, and J.P. Eissen. 1999a. Largest historic explosive eruption in the Andes at Huaynaputina volcano, south Peru. Geology 27 (5): 435-438.

Thouret, J.-C., G. Enjolras, K. Martelli, O. Santoni, J. Luque, M. Nagata, A. Arguedas, and L. Macedo. 2013. Combining criteria for delineating lahar-and flashflood-prone hazard and risk zones for the city of Arequipa, Peru. Natural Hazards and Earth System Sciences 13 (2): 339.

Thouret, J.C., A. Finizola, M. Fornari, A. Legeley-Padovani, J. Suni, and M. Frechen. 2001. Geology of el Misti volcano near the city of Arequipa, Peru. Geological Society of America Bulletin 113 (12): 1593-1610.

Thouret, J.C., F. Legros, A. Gourgaud, G. Salas, E. Juvigné, E. Gilot, M. Uribe, and A. Rodriguez. 1995. Un exemple de prévision des risques volcaniques au Pérou méridional (région d'Arequipa), fondé sur l'étude de l'activité éruptive récente du strato-volcan El Misti. Compte-Rendus Académie Sciences (Géomatériaux) 320 (lla): 923-929.

Thouret, J.C., J. Suni, J.P. Eissen, and P. Navarro. 1999b. Assessment of volcanic hazards in the Arequipa area based on the eruptive history of Misti volcano, southern Peru. Zeitschrift für Geomorphology 114 (supplement): 89-112.

Tidball, K.G., M.E. Krasny, E. Svendsen, L. Campbell, and K. Helphand. 2010. Stewardship, learning, and memory in disaster resilience. Environmental Education Research 16 (5-6): 591-609.

Vargas Franco, R., J.-C. Thouret, G. Delaite, C. van Westen, M. F. Sheridan, C. Siebe, J. Mariño, T. Souriot, and A. Stinton. 2010. Mapping and assessing volcanic hazards and risks in the city of Arequipa, Peru, based on GIS techniques. In Stratigraphy and geology of volcanic areas, eds. G. Groppelli and L. ViereckGoette: Geological Society of America, Special Publication SPE464.

Wachinger, G., O. Renn, C. Begg, and C. Kuhlicke. 2013. The risk perception paradox_-Implications for governance and communication of natural hazards. Risk Analysis 33 (6): 1049-1065.
Wagner, W., G. Duveen, R. Farr, S. Jovchelovitch, F. Lorenzi-Cioldi, I. Marková, and D. Rose. 1999. Theory and method of social representations. Asian Journal of Social Psychology 2 (1): 95-125.

Weber, E., and C. Hsee. 2000. Culture and individual judgment and decision making. Applied Psychology 49 (1): 32-61.

Weinstein, N.D. 1989. Effects of personal experience on self-protective behavior. Psychological Bulletin 105 (1): 31-50.

Zhai, G., T. Sato, T. Fukuzono, S. Ikeda, and K. Yoshida. 2006. Willingness to pay for flood risk reduction and its determinants in Japan. Journal of the American Water Resources Association 42 (4): 927-940.

Zonabend, F. 1989. La presqu'île au nucléaire. Paris: Odile Jacob.

\section{Submit your manuscript to a SpringerOpen ${ }^{\circ}$ journal and benefit from:}

- Convenient online submission

- Rigorous peer review

- Open access: articles freely available online

- High visibility within the field

- Retaining the copyright to your article

Submit your next manuscript at springeropen.com 